City University of New York (CUNY)

CUNY Academic Works

2019

\title{
Adolescent obesity in the past decade: A systematic review of genetics and determinants of food choice
}

Eleanor T. Campbell
CUNY Lehman College

Alexis T. Franks

National Institutes of Health $(\mathrm{NIH})$

Paule V. Joseph

National Institutes of Health (NIH)

\section{How does access to this work benefit you? Let us know!}

More information about this work at: https://academicworks.cuny.edu/le_pubs/343

Discover additional works at: https://academicworks.cuny.edu

This work is made publicly available by the City University of New York (CUNY).

Contact: AcademicWorks@cuny.edu 


\title{
Adolescent obesity in the past decade: A systematic review of genetics and determinants of food choice
}

\author{
Eleanor T. Campbell, EdD, RN, FNYAM (Associate Professor),
} Fellow) $^{3}$, \& Paule V. Joseph, PhD, MS, FNP-BC, CTN-B (Assistant Clinical Investigator and Chief) ${ }^{3}$

\begin{abstract}
Background and purpose: As the incidence of global obesity increases, concerns about adverse health outcomes in adolescents continues to rise. The complexity and expense of this problem require early recognition and specific preventive treatments. Knowledge of genetics and determinants of food choices contributing to adolescent obesity warrants further examination. The primary goal was to appraise the literature from the past decade (2007-2017) on the current state of food choice and genetic determinants of adolescent overweight/obesity in the United States. The secondary goal was to determine trends in the literature and areas for future research.

Methods: A systematic review of research studies in the United States from 2007 to 2017 was completed. Database searches were conducted using CINAHL, Embase, PsycINFO, PsycArticles, PubMed, Scopus, Academic Search Complete, Web of Science, BIOSIS, and the Cochrane Library. A total of 535 studies were selected. Of these, 283 studies focused on determinants of food choices and 165 studies focused on genetic factors.

Conclusions: A total of 41 full-text articles included in this literature review contained studies limited exclusively to adolescents. Stress factors related to food choices demonstrated a new trend being explored. The need for precision health, the application of genetic information, could uncover ways food choices affect adolescent obesity.

Implications for practice: The etiology of adolescent obesity requires that nurses gain knowledge of genetics and food choice determinants to inform personalized treatments for adolescents, which may establish effective interventions that promote healthy weight achievement.
\end{abstract}

Keywords: Adolescence; childhood; food choices; genetics; health disparities; obesity.

Journal of the American Association of Nurse Practitioners 31 (2019) 344-351, @ 2019 The Authors. Published by Wolters Kluwer on behalf of the American Association of Nurse Practitioners

DOI\# 10.1097/JXX.0000000000000154

\section{Introduction}

Adolescents and young adults comprise one fifth of the U.S. population. According to U.S. Census Bureau's estimates in $2012,14 \%$ of the total U.S. population consists of adolescents aged $10-19$ years, including $41,844,000$ youth (21.3 million males and 20.3 million females) (Bureau USC, 2013). Adolescents have distinct physical, cognitive, and

\footnotetext{
${ }^{1}$ Department of Nursing, Lehman College, City University of New York, Bronx, New York ${ }^{2}$ The Graduate Center, City University of New York, New York City, New York ${ }^{3}$ Sensory Science and Metabolism Unit,

Biobehavioral Branch, Division of Intramural Research, Department of Health and Human Services (DHHS), National Institute of Nursing Research (NINR), National Institutes of Health (NIH), Bethesda, Maryland This is an open access article distributed under the terms of the Creative Commons Attribution-Non Commercial-No Derivatives License 4.0 (CC BY-NC-ND), which permits downloading and sharing the work provided it is properly cited. The work cannot be changed in any way or used commercially without permission from the journal.

Correspondence: Eleanor T. Campbell, EdD, RN, FNYAM, 250 Bedford Park Blvd W, Bronx, NY 10468. Tel: 718-960-8393; E-mail: eleanor. campbell@lehman.cuny.edu
}

Received: 7 August 2018; accepted 20 September 2018 emotional characteristics, such as rapid physical growth, brain development, and hormonal changes that affect their caloric needs, cognition (abstract thinking and moral reasoning), and metabolism, respectively (Papalia \& Martorell, 2015). However, these unique biological and developmental changes may pose a risk for obesity, which, in turn, increases their risk for comorbidities with advancing age, including cardiovascular disease (CVD) (Reilly \& Kelly, 2011), sleep apnea (Kheirandish-Gozal, Peris, \& Gozal, 2014), type 2 diabetes (T2D) (Reilly \& Kelly, 2011), and psychosocial problems, that is, poor selfesteem and low quality of life (Daniels et al., 2005; Freedman, Mei, Srinivasan, Berenson, \& Dietz, 2007).

Obesity remains prevalent in U.S. youth. In 2011-2012, data from the National Health and Nutrition Examination Survey revealed that $20.5 \%$ of youth aged $12-19$ years were obese (Ogden, Carroll, Kit, \& Flegal, 2014), and these rates continue to increase (USDHHS, 2017). Obesity results from interactions of both environmental and biological factors

(Figure 1). Biological factors can be used to inform and 


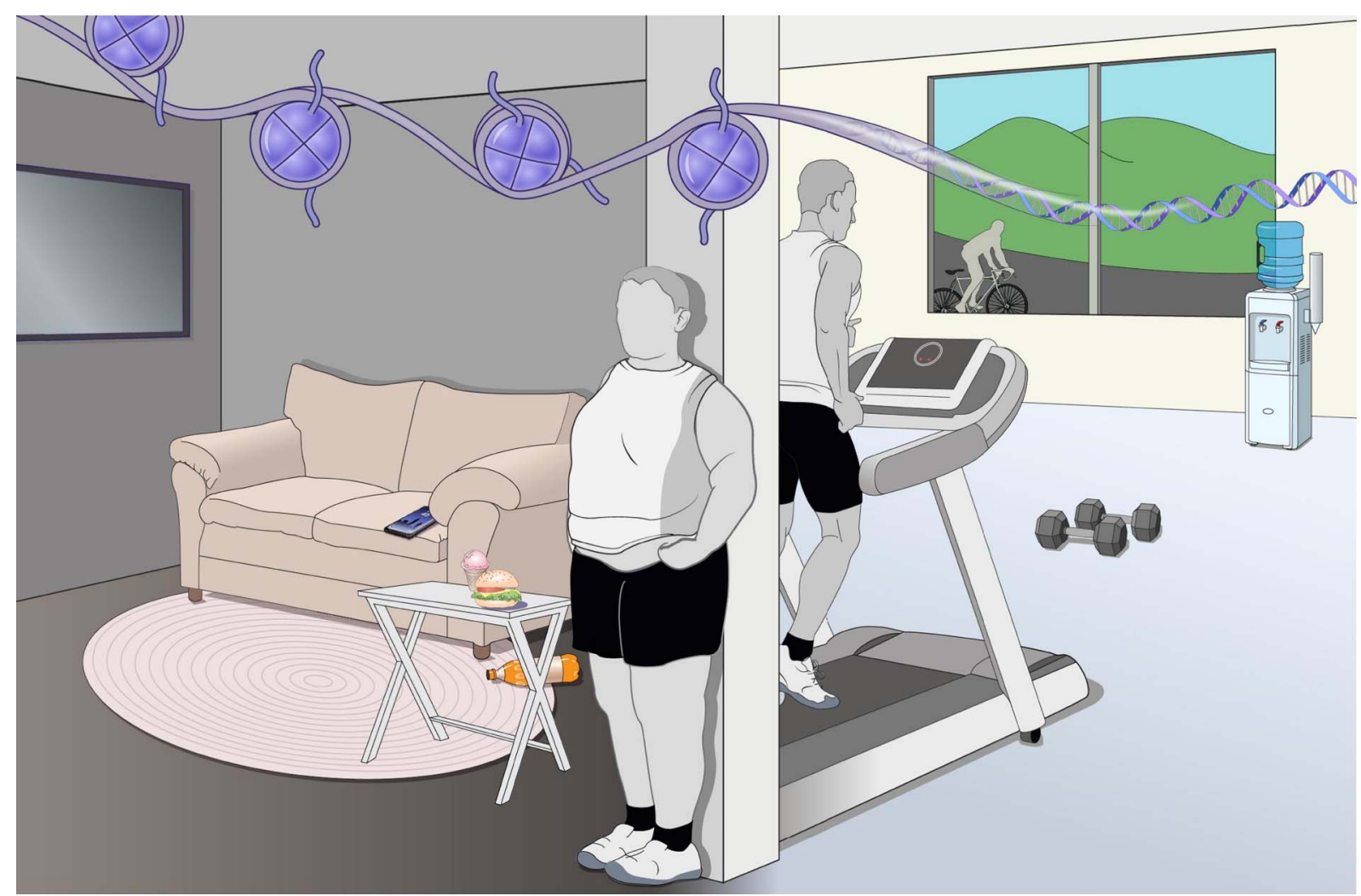

Figure 1. Environment and genetic factors in adolescent obesity.

change food choices that may contribute to obesity-related diseases. Environmental factors, such as social influences (culture, friends, and family) and socioeconomic status (SES), have demonstrated relationships with overweight and obesity (Ogden, Carroll, Fryar, \& Flegal, 2015). Epigenetic effects, chemical alterations in DNA, are known to be linked to the development of diseases, including obesity (van Dijk et al., 2015). Furthermore, biological factors, such as genetic inheritance also affect obesity development. Obesity risk is two to eight times higher for individuals with a family history of obesity as opposed to an individual without a family history of obesity (Delrue \& Michaud, 2004; Qi \& Cho, 2008).

Although the prevalence of obesity in the United States has sparked extensive research in both environmental and genetic causes (CDC, 2011; Ogden et al., 2015), little research has been conducted on adolescent's food choices. Adolescents are often combined with either adults or children of all ages. Aggregating age groups limits data analysis for adolescents who have particular physical and developmental characteristics that can influence behaviors and require different approaches to therapeutic interventions. Thus, the purpose of this review was twofold: first, we appraised the literature from the past decade (2007-2017) on the current state of the science of environmental and genetic determinants of adolescent overweight/obesity in the United States, and second, we determined trends in the literature and new areas for future research.

\section{Methods}

\section{Search strategy}

This systematic review followed the Preferred Reporting Items for Systematic Reviews and Meta-Analyses (PRISMA) guidelines (Liberati et al., 2009). Database searches were conducted using CINAHL, Embase, PsycINFO, PsycArticles, PubMed, Scopus, Academic Search Complete, Web of Science, BIOSIS, and the Cochrane Library. We selected a list of search terms based on a preliminary search of the literature. For the adolescent food choice search, the following Boolean search terms were used: Determinants OR influences AND food AND choice OR selections AND teen OR adolescent AND US OR united states. For the genetic search, the following search terms were used: Genetic markers AND obesity AND adolescent AND United States. In addition to the above databases, we searched reference lists of included studies found during the search process.

Our inclusion and exclusion criteria follow the Centers for Disease Control and Prevention's definition of adolescence; age range between 10 and 19 years was considered for the inclusion criteria. Studies were limited to those in English and based in the United States. All studies were published in peer-reviewed journals within the past 10 years (2007-2017). In addition, studies that included both children and adolescents or both adolescents and adults 
were excluded unless they explicitly analyzed adolescents separately, with the exception of genetic studies. Titles, abstracts, and full-text articles were reviewed for relevance independently by two authors. Discrepancies were resolved by a third author. Conference abstracts, reviews, and book chapters identified through database searches were excluded at the screening stage.

\section{Data extraction and study quality assessment}

Data from each reviewed article (study design, sample size, setting, age, race/ethnicity, primary purpose, major variables studied, definitions, measurements, data analysis, and study findings) were extracted by two authors independently (ETC, ATF and/or PVJ) and placed into standardized tables (Table 1, Supplemental Digital Content 1, available at http:/ / links.lww.com/JAANP/A21). Study quality was also determined by the authors.

\section{Results}

\section{Study selection}

The initial search yielded 535 articles, of which 359 were assessed by title/abstract after removing the duplicates. Of these, the full texts of 171 articles were assessed. Studies were excluded based on age of participants, location outside United States, and study design (nonresearch-based). The final number of articles included in this review is 41 (Figure 2).

\section{Participant characteristics}

The number of participants per study ranged from 7 to 5,203 (Table 1, Supplemental Digital Content 1, available at http:// links.lww.com/JAANP/A21). All the studies $(n=41)$ were conducted in the United States. The majority of the food choice studies included convenience samples and participants aged 9-18 years, whereas the biological studies consisted of participants mostly between ages 4-19 years. None of the studies included randomized sampling. Most studies included both males and females, with three focused on a female cohort only. A variety of races and ethnicities were included among the studies, including European American or White, African American or Black, Asian American, and Mexican American or Hispanic individuals. Quantitative studies dominated at 32 and there were nine qualitative studies. The majority of study designs were descriptive $(n=12)$. There was one longitudinal study and one experimental study (Table 1, Supplemental Digital Content 1, available at http:/ / links.Iww.com/JAANP/A21).

\section{Determinants of food choices}

Culture. Two studies of Asian American adolescents included food choice comparisons between Hmong Chinese immigrants and U.S.-born Hmong American adolescents. The subgroup of Asian Americans has been identified as having higher rates of overweight and obesity than other ethnic Asians. Both studies concluded that assimilation to the American diet of higher consumption of high-fat and high-calorie foods contributed to the obesity among the Chinese participants (Franzen \& Smith, 2009; MulasiPokhriyal \& Smith, 2011; Stang, Kong, Story, Eisenberg, \& Neumark-Sztainer, 2007). Such findings are consistent with studies of other ethnic immigrant groups including Mexican-Americans (Franzen \& Smith, 2009; MulasiPokhriyal \& Smith, 2011; Stang et al., 2007).

Stress. Stress in the home was another theme in several studies (Senguttuvan, Whiteman, \& Jensen, 2014; Winkler, Moore, Bennett, Armstrong, \& Brandon, 2017; Zeller et al., 2007). Stress was associated with ineffective coping strategies such as binge eating and sedentary behaviors like higher television viewing time. Adolescents living in singleparent households either alone or with other siblings experienced more stress than those living with both parents. In addition, nonsanguineous siblings residing in blended families experienced higher levels of stress than those residing within nuclear families (Zeller et al., 2007). More mealtime stress was associated with parents and obese children regardless of race or SES (Zeller et al., 2007).

Sibling relationships and family structure. Sibling relationships was a third theme found in the studies. Positive sibling relationships were associated with less binge eating and less overweight and obesity compared with poor sibling relationships where competition with parents was an issue (Senguttuvan et al., 2014). Sibling gender was not a significant variable, however, age proximity (2-4 years) was a factor in supporting positive relationships and support for healthy food choices versus ineffective coping strategies for stress such as binge eating (Senguttuvan et al., 2014). Family beliefs and practices of parents influenced the food choices of nonimmigrant children and adolescents (Travis, Bisogni, \& Ranzenhofer, 2010).

Education. Several pre- and post-nutrition education comparison studies supported the short-term impact of focused education on healthy food choices. Supports, such as school gardens, are paving the way for increased awareness for community-specific education sessions (Wansink, Hanks, \& Just, 2015). Studies on the impact of menu boards on food choices revealed a high interest by high school students knowing which foods are best for individual nutrition needs (Wansink et al., 2015).

Socioeconomic status and communities. By far, the SES of adolescents and their families strongly contributed to their food choices. The financial status of teens affected the community of residence, which in turn dictated the types and quality of foods available for purchase. Socioeconomic status determined the type of school and educational resources available to the adolescents as well. This factor alone was the greatest predictor of food choices in all studies (Evans et al., 2016).

Study types. Quantitative studies still dominate the research method in most of the research that examined relationships between cause and impact on food choices 


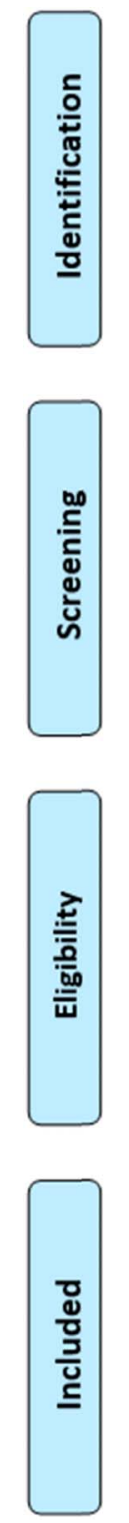

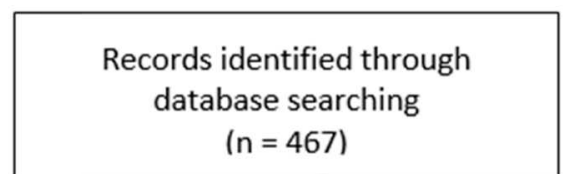

$(n=467)$
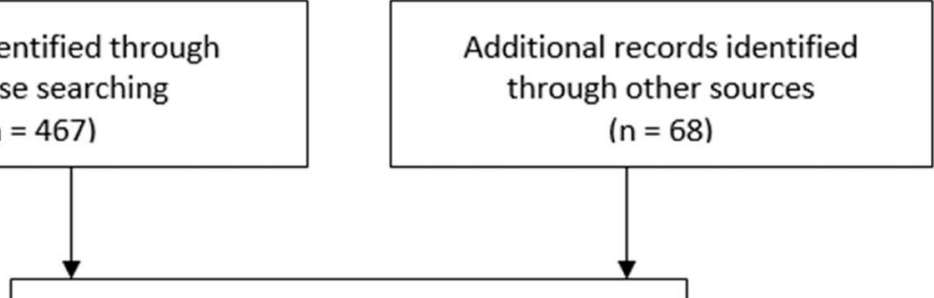

Records after duplicates removed

( $n=291$ )
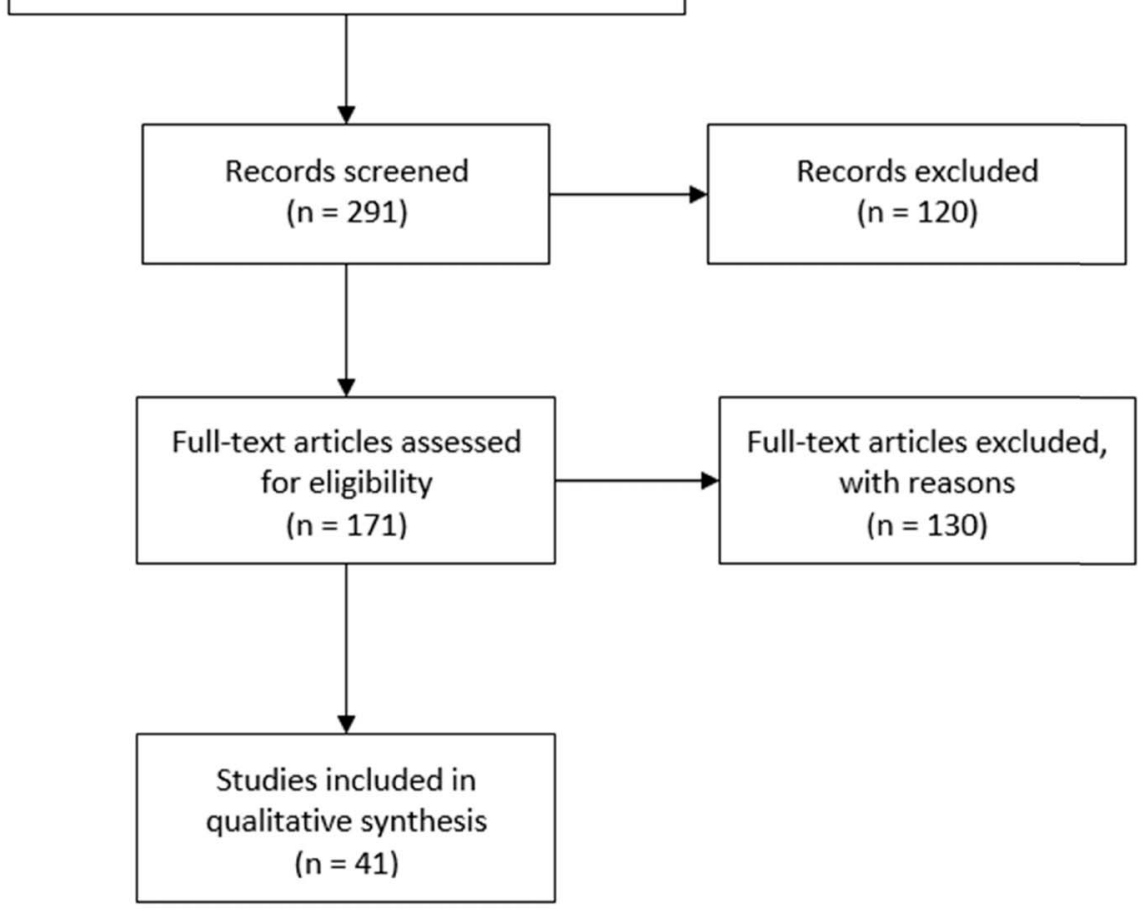

Figure 2. PRISMA flow chart of study inclusion. PRISMA = Preferred Reporting Items for Systematic Reviews and Meta-Analyses.

and overweight or obesity. A total of 18 quantitative compared with six qualitative studies were found in this search. Instruments used in these studies were generally investigator designed with limited or no reliability data, making outcome comparisons more difficult.

Conceptual models. Social cognitive theory was the most frequently used conceptual model. This model was explained as the best fit for the research study focus. Most studies did not use a conceptual model and because most had small sample sizes of less than 100 participants, this made study comparisons difficult.

\section{Genetic studies}

Study type. The majority of the articles $(n=12)$ were genome-wide association studies (GWAS), and four were cross-sectional studies. Most of the studies included both children and adolescents (ages 4-19 years) and did not separate the analyses by the different cohorts.

Ethnicity. The most prevalent studies $(n=10)$ reviewed were secondary analyses of the Viva La Familia Study, a GWAS examining the numerous biological factors affecting obesity within a Hispanic cohort. Five of the articles focused on both African American and non-Hispanic White cohorts and two included data on Asian American participants.

Anthropometric measurements. Anthropometric measurements, or measurements related to the human body, such as body mass index (BMI), body composition, fat mass (FM), weight, and height were associated with various biological or genetic factors affecting obesity in adolescence. For instance, the FM and obesity (FTO) associated gene was correlated with a $0.27 \mathrm{~kg} / \mathrm{m}^{2}$ increase of BMI in adolescents from grades 7 to 12 
(McQueen et al., 2014). Body mass index and waist circumference were also associated with variables, such as single-nucleotide polymorphisms (SNPs) (differences in a single nucleotide) on solute carrier protein 2, family member 9 (SLC2A9) (Voruganti et al., 2015).

Furthermore, insulin-induced gene 2 (INSIG2) polymorphisms, such as the rs17047757 SNP, demonstrated significance in the overweight group of non-Hispanic White individuals (Kaulfers, Deka, Dolan, \& Martin, 2015). Weight $z$-score changes were associated with a variant in the collagen type IV alpha 1 chain (COL4A1) gene on chromosome 13 (Comuzzie et al., 2012). Also, repeated lengths of the trinucleotide CAG on the androgen receptor (AR) gene were inversely related to weight in a female cohort but were positively associated with height in both lean and obese males (Butler \& Manzardo, 2015).

Genetic markers and variants. Common reported chromosomes in the reviewed literature associated with adolescent obesity were chromosomes 11, 13, and 19. A chromosome is a thread-like structure of DNA (nucleic acids and proteins) that carries genes (Alberts et al., 2002). As evident, multiple markers found in genes on chromosome 11 are related to fasting glucose [melatonin receptor 1B (MTNR1B) gene], triglyceride [apolipoprotein A-V zinc finger gene cluster 249 (APOA5-ZNF249) region] (Comuzzie et al., 2012) and adiponectin levels (between markers D11S925 and D11S968) (Tejero et al., 2007). Chromosome 13 is also associated with variants on the COL4A1 gene, which encodes collagen (Comuzzie et al., 2012). Furthermore, the megakaryocyte-associated tyrosine kinase (MATK) gene on chromosome 19 is associated with total energy expenditure (Comuzzie et al., 2012). Genetic variants found in the MATK gene and COL $4 A 1$ genes are both related to obesity pathogenesis (Comuzzie et al., 2012). In addition, chromosome 13 (between markers D13S158-D19S221) and chromosome 19 (near marker D7S657) are both associated with fasting serum glucose (FSG), which is linked with obesogenic and diabetogenic phenotypes (Cai, Cole, Butte, Voruganti, \& Comuzzie, 2007).

Several studies focused on other genetic influences, such as the patatin-like phospholipase domain containing protein 3 (PNPLA3) and apolipoprotein C3 (APOC3) genes, which were both associated with increases in liver fat content, inflammation, and the male gender (Walker et al., 2013). Also, increased methylation, or addition of a methyl group to cytosine (a nitrogenous base), of the CpG site [dinucleotide pair of cytosine and guanine ( $C$ and $G$ )] in the lymphocyte antigen 86 (LY86) gene occurred in obese individuals (Su et al., 2014). The methylation levels in the LY86 region were associated with adiposity, insulin resistance, and inflammation (Su et al., 2014).

Additionally, copy number variants (CNVs) near various genes demonstrated racial differences. For instance, deletions in CNVs near the deoxyribose-phosphate aldolase (DERA), pancreatic lipase related protein 1
(PNLIPRP1), and centaurin-delta 1 (CENTD1) genes were all exclusive to European Americans (Glessner et al., 2010). Deletions of CNVs on genes, including sphingosine 1 phosphate receptor 5 (SP1PR5), forkhead box P2 (FOXP2), tubilin-specific chaperone $A$ (TBCA), and ATP-binding cassette, subfamily $B$, member 5 ( $A B C B 5$ ), were demonstrated in both European and African Americans (Glessner et al., 2010). However, duplications of CNVs on kinesin family member 2B (KIF2B) and ADP-ribosylation factorlike 15 (ARL15), which is related to adiponectin levels, were exclusive to both European and African Americans (Glessner et al., 2010). Also, variants in the gene INSIG2, specifically SNPs rs17047757 and rs12464355, which affects lipid regulation, were significant in overweight/obese non-Hispanic White children (Kaulfers et al., 2015).

Genetic loci. Genetic loci, or position on a chromosome, were also significant in the reviewed literature. For example, locus 10q22 contains genes that influence birth weight, body size, and CVD risk in Hispanic children (Cai, Cole, Haack, Butte, \& Comuzzie, 2007). Genetic markers on chromosome 13q, such as D13S158-D13S173, were associated with FSG (Cai, Cole, Butte, et al., 2007).

\section{Discussion}

These studies highlighted various ways in which adolescents' food choices and genetic markers predispose them to overweight and obesity. Although educational interventions showed some short-term positive outcomes on nutritional knowledge (food labels, menu boards, peer socialization), the long-term impact factor was minimal or unable to be determined. Only one longitudinal study was found in this literature review (Winkler et al., 2017). This study focused on the parenting styles of obese mothers and their influence on the daily food choices of obese daughters. Financial independence was a significant factor on influencing food choices, especially snack foods. Also, taste was a strong factor in food selections, which were influenced by ethnic/family culture for breakfast and dinner meals and peer groups for lunch and snack foods (Holsten, Deatrick, Kumanyika, Pinto-Martin, \& Compher, 2012; Swanson, Schoenberg, Davis, Wright, \& Dollarhide, 2013). The prevalence of more convenience stores in many low-income communities continue to affect the frequency of purchase of certain snack foods and sugary beverages (Wong et al., 2015). Cultural beliefs, values, and assimilation to the U.S. impact of food choices-being American versus belonging to an ethnic subgroup. The transition to the American diet of higher processed foods containing more trans fats, sugar, salt, and larger portion sizes, and especially snack foods and beverages were strong contributions to obesity for adolescent immigrant groups (Travis et al., 2010). Several studies highlighted the emotional impact of family types, both nuclear and blended, on parent and adolescent coping behaviors related to meals and binge eating (FieldingSingh, 2017; Senguttuvan et al., 2014; Zeller et al., 2007). 
In addition, the genetic search results showed significance regarding the FTO and INSIG2 genes. Previous studies reported that the relationship between $\mathrm{BMI}$ and the INSIG2 gene vary, but replications within the FTO gene proved to be significant (Hunt et al., 2008). Aside from the FTO gene being associated with BMI, previous studies reported correlations in the FTO gene, specifically the rs9939609 risk A-allele, to eating behaviors and food reward (Obregon Rivas, Santos, Valladares, Cameron, \& Goldfield, 2018). These results are differentiated in gender and ethnic group. For instance, males who were A-allele carriers demonstrated higher food response, emotional overeating, and food enjoyment compared with their female counterparts, especially Hispanic children (Castellini et al., 2017; Obregon Rivas et al., 2018). Also, the FTO gene is highly expressed within the hypothalamic region of the brain, which is correlated with appetite regulation and contributes to its association with eating disorders, specifically binge eating (Castellini et al., 2017).

Furthermore, although our search terms did not specifically include epigenetic alterations, one study demonstrated changes in DNA methylation levels (Su et al., 2014). Additionally, the genetic results displayed a research gap regarding the limited articles of genetic influences solely on adolescent obesity. As evident, majority of the genetic results demonstrated combinations of children and adolescents suggesting the need for more studies.

\section{Conclusion}

Adolescent obesity is a complex disease that includes both environmental and genetic factors. Studying interactions between genetic markers and food choices for the growing and changing adolescent may provide an insight on mechanisms that can be targeted on how to best care for this population. In summary, the findings of this review indicate that there is a huge gap in the literature when it comes to genetic studies focused on adolescents. Questions that tease out behavioral and genetic/genomic influences of adolescent obesity continue to be an area of inquiry. For example, is the reason for higher rates of overweight and obesity among African Americans and Hispanics in the United States due to food choices within certain zip codes or genetics? Research shows that ethnic and socioeconomic groupings that have similar cultural food practices, level of education, political power, and economic capital, share similar health behaviors and health outcomes (Pampel, Krueger, \& Denney, 2010). Similarly, genetic markers for slower metabolism have the potential to pose risks for overweight and obesity. As shown, the positive results for the FTO gene correspond to previous findings, which associated the FTO gene with BMI in the 95th percentile within a pediatric cohort (Fawcett \& Barroso, 2010; Hess \& Bruning, 2014; McQueen et al., 2014). Also, there are positive associations between INSIG2 and adolescent BMI, which contributes to the ongoing debate about INSIG2 being a determinant of BMI (Kaulfers et al., 2015; Talbert et al., 2009).

In addition, this literature review shows the continued trend in overweight and obesity related to the Western diet of highly processed, energy dense foods (Ayala et al., 2007; Bowen \& Devine, 2011; Franzen \& Smith, 2009; Gonzales, Laurent, \& Johnson, 2017; Stang et al., 2007). More progressive and long-term emotional as well as physical comorbidities are being identified as scientists continue to explore adolescent obesity. Understanding the relationship between personal health indicators (genetic markers) can help the public to modify their behaviors (food choices) more specifically in advance of negative health outcomes, such as overweight and obesity. The environmental factors for healthy and unhealthy food choices are constantly competing. Preventive measures such as targeted nutrition and exercise education have limited short-term effects (Kelishadi et al., 2014; Qi, 2014) Although government-sponsored nutrition-dense meals are available in schools, commercial competition from the fast food and convenience food industries present persistent barriers to abate the obesity epidemic. Management of overweight and obesity by the medical community has largely focused on diagnosis and treatment of the comorbidities associated with obesity rather than with preventive measures. Type-2 diabetes, depression, sleep apnea, and hypertension that accompany obesity are frequently managed using pharmacotherapy and surgical interventions for very obese adolescents. The use of precision health means predicting and mitigating overweight and obesity and associated health risks before they cause more health problems. It includes understanding the individual's biological risks that their environment can exacerbate and working with an interdisciplinary team to help change the environment to one that promotes and supports healthy weight (Gillman \& Hammond, 2016; Yanovski \& Yanovski, 2018).

\section{Implications and contributions}

If adolescent overweight and obesity are to be diminished and sustained, a holistic approach will be necessary. The advanced practice nurse (APRN) is a key to collaborate with geneticists, endocrinologists, public health advocates, and the snack food and beverage industry. Using the combined sciences of genetics and food choice determinants to identify and minimize the genetic markers health risks and effectively educating adolescents and their families about these two variables in their personal life will need to be done by APRNs. The role of the APRN includes health maintenance and prevention of disease through education of children and families. The role also includes being an advocate for ethical policies that affect social determinants of health (NONPF, 2017). More longitudinal studies that combine genetic and food 
choice analyses will need to be designed to better understand the co-contributing factors that increase and decrease adolescent obesity rates and T2D and other comorbidities. Currently, bariatric surgery is the preferred treatment for obese adolescents who have one or more comorbidities (Hsia, Fallon, \& Brandt, 2012). This is a costly and invasive intervention that could be avoided with more combined research on environment and genetics. Precision health would be a more proactive plan of care for genetically and behaviorally at-risk adolescents.

Acknowledgments: The authors would like to acknowledge funding from the U.S. Department of Health, National Institutes of Health, National Institutes of Nursing Research, Division of Intramural Research (to PVJ and Intramural Research Training Award to ATF), NIH, DHHS, Bethesda, MD. In addition, the authors would like to thank Ms. Brigit S. Sullivan, MLS, Biomedical Librarin at The National Institutes of Health Library.

Authors' contributions: All authors contributed equally to the conception, design, and acquisition of the revised manuscript.

\section{Competing interests: The authors report no conflicts of} interest.

\section{References}

Alberts, B., Johnson, A., Lewis, J., Raff, M., Robets, K., \& Walter, P. (2002). Molecular biology of the cell (4th ed.). New York, NY: Garland Science.

Ayala, G. X., Baquero, B., Arredondo, E. M., Campbell, N., Larios, S., \& Elder, J. P. (2007). Association between family variables and Mexican American children's dietary behaviors. Journal of Nutrition Education and Behavior, 39, 62-69.

Bowen, R. L., \& Devine, C. M. (2011). “Watching a person who knows how to cook, you'll learn a lot." Linked lives, cultural transmission, and the food choices of Puerto Rican girls. Appetite, 56, 290-298.

Bureau, U. S. C. (2013). Annual estimates of the resident population for selected age groups by sex for the United States, states, counties, and Puerto Rico Commonwealth and Municpios: April 1, 2010 to July 1, 2015. American Fact Finder. Retrieved from https:/ / factfinder. census.gov/faces/tableservices/jsf/pages/productview.xhtml? $\mathrm{src}=\mathrm{bkmk}$.

Butler, M. G., \& Manzardo, A. M. (2015). Androgen receptor (AR) gene CAG trinucleotide repeat length associated with body composition measures in non-syndromic obese, non-obese and Prader-Willi syndrome individuals. Journal of Assisted Reproduction and Genetics, 32, 909-915.

Cai, G., Cole, S. A., Butte, N. F., Voruganti, V. S., \& Comuzzie, A. G. (2007). A quantitative trait locus on chromosome $13 q$ affects fasting glucose levels in Hispanic children. Journal of Clinical Endocrinology and Metabolism, 92, 4893-4896.

Cai, G., Cole, S. A., Haack, K., Butte, N. F., \& Comuzzie, A. G. (2007). Bivariate linkage confirms genetic contribution to fetal origins of childhood growth and cardiovascular disease risk in Hispanic children. Hum Genet, 121, 737-744.

Castellini, G., Franzago, M., Bagnoli, S., Lelli, L., Balsamo, M., Mancini, M., et al (2017). Fat mass and obesity-associated gene (FTO) is associated to eating disorders susceptibility and moderates the expression of psychopathological traits. PLoS One, 12, e0173560.
CDC. (2011). Healthy people 2020. Centers for Disease Control and Prevention.

Comuzzie, A. G., Cole, S. A., Laston, S. L., Voruganti, V. S., Haack, K., Gibbs, R. A., et al (2012). Novel genetic loci identified for the pathophysiology of childhood obesity in the hispanic population. PLoS One, 7 e51954.

Daniels, S. R., Arnett, D. K., Eckel, R. H., Gidding, S. S., Hayman, L. L., Kumanyika, S., et al (2005). Overweight in children and adolescents: Pathophysiology, consequences, prevention, and treatment. Circulation, 111, 1999-2012.

Delrue, M. A., \& Michaud, J. L. (2004). Fat chance: Genetic syndromes with obesity. Clinical Genetics, 66, 83-93.

Evans, A. E., Weiss, S. R., Meath, K. J., Chow, S., Vandewater, E. A., \& Ness, R. B. (2016). Adolescents' awareness and use of menu labels in eating establishments: Results from a focus group study. Public Health Nutrition, 19, 830-840.

Fawcett, K. A., \& Barroso, I. (2010). The genetics of obesity: FTO leads the way. Trends in Genetics, 26, 266-274.

Fielding-Singh, P. (2017). Dining with dad: Fathers' influences on family food practices. Appetite, 117, 98-108.

Franzen, L., \& Smith, C. (2009). Acculturation and environmental change impacts dietary habits among adult Hmong. Appetite, 52, 173-183.

Freedman, D. S., Mei, Z., Srinivasan, S. R., Berenson, G. S., \& Dietz, W. H. (2007). Cardiovascular risk factors and excess adiposity among overweight children and adolescents: The Bogalusa Heart Study. The Journal of Pediatrics, 150, 12-17.e12.

Gillman, M. W., \& Hammond, R. A. (2016). Precision treatment and precision prevention: Integrating "below and above the skin". Journal of American Medical Association Pediatrics, 170, 9-10.

Glessner, J. T., Bradfield, J. P., Wang, K., Takahashi, N., Zhang, H., Sleiman, P. M., et al (2010). A genome-wide study reveals copy number variants exclusive to childhood obesity cases. American Journal of Human Genetics, 87, 661-666.

Gonzales, R., Laurent, J. S., \& Johnson, R. K. (2017). Relationship between meal plan, dietary intake, body mass index, and appetitive responsiveness in College students. Journal of Pediatric Health Care, 31, 320-326.

Hess, M. E., \& Bruning, J. C. (2014). The fat mass and obesity-associated (FTO) gene: Obesity and beyond? Biochimica et Biophysica Acta, 1842, 2039-2047.

Holsten, J. E., Deatrick, J. A., Kumanyika, S., Pinto-Martin, J., \& Compher, C. W. (2012). Children's food choice process in the home environment. A qualitative descriptive study. Appetite, 58, 64-73.

Hsia, D. S., Fallon, S. C., \& Brandt, M. L. (2012). Adolescent bariatric surgery. Arch Pediatr Adolesc Med, 166, 757-766.

Hunt, S. C., Stone, S., Xin, Y., Scherer, C. A., Magness, C. L., Iadonato, S. P., et al (2008). Association of the FTO gene with BMI. Obesity, 16, 902-904.

Kaulfers, A. M., Deka, R., Dolan, L., \& Martin, L. J. (2015). Association of INSIG2 polymorphism with overweight and LDL in children. PLOS One, 10:e0116340.

Kelishadi, R., Minasian, V., Marandi, S. M., Farajzadegan, Z., Khalighinejad, P., Shirdavani, S., et al (2014). Short-term effects of a physical activity intervention on obesity and aerobic fitness of adolescent girls. International Journal of Preventive Medicine, 5, S108-S113.

Kheirandish-Gozal, L., Peris, E., \& Gozal, D. (2014). Vitamin D levels and obstructive sleep apnoea in children. Sleep Medicine, 15, 459-463.

Liberati, A., Altman, D. G., Tetzlaff, J., Mulrow, C., Gotzsche, P. C., Ioannidis, J. P., et al (2009). The PRISMA statement for reporting systematic reviews and meta-analyses of studies that evaluate health care interventions: Explanation and elaboration. Journal of Clinical Epidemiology, 62, e1-34.

McQueen, M. B., Boardman, J. D., Domingue, B. W., Smolen, A., Tabor, J., Killeya-Jones, L., et al (2014). The national longitudinal study of adolescent to adult health (add health) sibling pairs genome-wide data. Behavior Genetics, 45, 12-23.

Mulasi-Pokhriyal, U., \& Smith, C. (2011). Investigating health and diabetes perceptions among Hmong American children, 9-18 years of age. Journal of Immigrant and Minority Health, 13, 470-477.

NONPF. (2017). Competencies for nurse practitioners. The National Organization of Nurse Practitioner Faculties. 
Obregon Rivas, A. M., Santos, J. L., Valladares, M. A., Cameron, J., \& Goldfield, G. (2018). Association of the FTO fat mass and obesityassociated gene rs9939609 polymorphism with rewarding value of food and eating behavior in Chilean children. Nutrition, 54, 105-110.

Ogden, C. L., Carroll, M. D., Fryar, C. D., \& Flegal, K. M. (2015). Prevalence of obesity among adults and youth: United States, 2011-2014. NCHS Data Brief, 1-8.

Ogden, C. L., Carroll, M. D., Kit, B. K., \& Flegal, K. M. (2014). Prevalence of childhood and adult obesity in the United States, 2011-2012. Journal of American Medical Association, 311, 806-814.

Pampel, F. C., Krueger, P. M., \& Denney, J. T. (2010). Socioeconomic disparities in health behaviors. Annual Review of Sociology, 36, 349-370.

Papalia, D., \& Martorell, G. (2015). Experience human development (13th ed. ed.). New York, NY: McGraw-Hill Education.

Qi, L. (2014). Personalized nutrition and obesity. Annals of Medicine, $46,247-252$.

Qi, L., \& Cho, Y. A. (2008). Gene-environment interaction and obesity. Nutrition Reviews, 66, 684-694.

Reilly, J. J., \& Kelly, J. (2011). Long-term impact of overweight and obesity in childhood and adolescence on morbidity and premature mortality in adulthood: Systematic review. Int I Obes (Lond), 35, 891-898.

Senguttuvan, U., Whiteman, S. D., \& Jensen, A. C. (2014). Family relationships and adolescents' health attitudes and weight: The understudied role of sibling relationships. Federal Register, 63, 384-396.

Stang, J., Kong, A., Story, M., Eisenberg, M. E., \& Neumark-Sztainer, D. (2007). Food and weight-related patterns and behaviors of Hmong adolescents. Journal of The American Dietetic Association, 107, 936-941.

Su, S., Zhu, H., Xu, X., Wang, X., Dong, Y., Kapuku, G., et al (2014). DNA methylation of the LY86 gene is associated with obesity, insulin resistance, and inflammation. Twin Research and Human Genetics, 17, 183-191.

Swanson, M., Schoenberg, N. E., Davis, R., Wright, S., \& Dollarhide, K. (2013). Perceptions of healthful eating and influences on the food choices of appalachian youth. Journal of Nutrition Education and Behavior, 45, 147-153.

Talbert, M. E., Langefeld, C. D., Ziegler, J. T., Haffner, S. M., Norris, J. M., \& Bowden, D. W. (2009). INSIG2 SNPS associated with obesity and glucose homeostasis traits in Hispanics: The IRAS family study. Obesity (Silver Spring), 17, 1554-1562.

Tejero, M. E., Cai, G., Goring, H. H., Diego, V., Cole, S. A., Bacino, C. A., et al (2007). Linkage analysis of circulating levels of adiponectin in Hispanic children. International Journal of Obesity (London), 31, 535-542.

Travis, S., Bisogni, C., \& Ranzenhofer, L. (2010). A conceptual model of how US families with athletic adolescent daughters manage food and eating. Appetite, 54, 108-117.

USDHHS. (2017). Nutrition and Weight Status. Retrieved from https:/ / www.healthypeople.gov/2020/topics-objectives/topic/nutritionand-weight-status.

van Dijk, S. J., Molloy, P. L., Varinli, H., Morrison, J. L., Muhlhausler, B. S., \& Members of Epi, S. (2015). Epigenetics and human obesity. International Journal of Obesity (London), 39, 85-97.

Voruganti, V. S., Laston, S., Haack, K., Mehta, N. R., Cole, S. A., Butte, N. F., et al (2015). Serum uric acid concentrations and SLC2A9 genetic variation in hispanic children: The Viva La Familia study. The American Journal of Clinical Nutrition, 101, 725-732.

Walker, R. W., Sinatra, F., Hartiala, J., Weigensberg, M., Spruijt-Metz, D., Alderete, T. L., et al (2013). Genetic and clinical markers of elevated liver fat content in overweight and obese hispanic children. Obesity, 21, E790-E797.

Wansink, B., Hanks, A. S., \& Just, D. R. (2015). A plant to plate pilot: A cold-climate high school garden increased vegetable selection but also waste. Acta Paediatrica, 104, 823-826.

Winkler, M. R., Moore, E. D., Bennett, G. G., Armstrong, S. C., \& Brandon, D. H. (2017). Parent-adolescent influences on everyday dietary practices: Perceptions of adolescent females with obesity and their mothers. Maternal and Child Nutrition, 13. doi:10.1111/mcn.12416.

Wong, M. S., Nau, C., Kharmats, A. Y., Vedovato, G. M., Cheskin, L. J., Gittelsohn, J., et al (2015). Using a computational model to quantify the potential impact of changing the placement of healthy beverages in stores as an intervention to "Nudge" adolescent behavior choice. BMC Public Health, 15, 1284.

Yanovski, S. Z., \& Yanovski, J. A. (2018). Toward precision approaches for the prevention and treatment of obesity. Journal of American Medical Association, 319, 223-224.

Zeller, M. H., Reiter-Purtill, J., Modi, A. C., Gutzwiller, J., Vannatta, K., \& Davies, W. H. (2007). Controlled study of critical parent and family factors in the obesigenic environment. Obesity (Silver Spring), 15, 126-136.

\section{Instructions for Earning CE Credit:}

- Read the article.

- The test for this CE activity can be taken online at www.NursingCenter.com/CE/JAANP. Find the test under the article title.

- You will need to create a username and password and login to your personal CE Planner account (It's free!) before taking online tests. Your planner will keep track of all your Lippincott Professional Development online CE activities for you.

- There is only one correct answer for each question. A passing score for this test is 13 correct answers. If you pass, you can print your certificate of earned contact hours and access the answer key. If you fail, you have the option of taking the test again at no additional cost.

- For questions, contact Lippincott Professional Development: 1-800-787-8985.

Registration Deadline: June 1, 2020.

\section{Disclosure Statement:}

The authors and planners have disclosed that they have no financial relationships related to this article.

\section{Provider Accreditation:}

This activity is approved for 1.5 contact hours of continuing education by the American Association of Nurse Practitioners. Activity ID 19053705. This activity was planned in accordance with AANP CE Standards and Policies. This activity is also provider approved by the California Board of Registered Nursing, Provider Number CEP 11749 for 1.5 contact hours. Lippincott Professional Development is also an approved provider of continuing nursing education by the District of Columbia Board of Nursing, Georgia Board of Nursing, and Florida Board of Nursing, CE Broker \#50-1223.

\section{Payment:}

- The registration fee for this test is $\$ 17.95$.

- AANP members are eligible for a $50 \%$ discount. Visit the member-benefit section on AANP website (https://aanp.org/membership/memberbenefits) to obtain the discount code. Use the code when asked for payment during checkout. 